\title{
Financial Risks and Bankability In EPC Contracts
}

\author{
Rahul Bali ${ }^{1}$ and Prof M.R Apte ${ }^{2}$ \\ ${ }^{l} M$. E Civil [C \& M] MIT College, Pune. \\ ${ }^{2}$ Guide \& Professors Civil Eng. Dept., MIT College, Pune.
}

\begin{abstract}
EPC contracts are the most common form of contract used to undertake construction works on large-scale. EPC Contractor has to deliver a complete facility for a guaranteed price by a guaranteed date and it must perform to the specified level. Failure to comply with any requirements will usually result in the contractor incurring monetary liabilities

Risks allocation between the contractor and the project company that satisfies the lenders are bankable contracts. Lenders prefer for one strong party to accept full responsibility, delivering the works on time, on budget and to meet the required technical and performance specification. At times EPC contractors act as a consortium. The work is divided between the parties, such split / cooperation is encouraged keeping intact the efficiency and single point responsibility. The key driver for adopting a split structure is also the tax efficacy considering all financial risks as well.

The EPC contract constitutes a large portion of the project cost. Therefore, apart from being satisfied that the project is financially viable, the primary interest of lenders during the pre-contract stage will be to ensure only well qualified credit worthy EPC contractors are considered.
\end{abstract}

Keywords: EPC Contract, Financial Risks, Lender, Bankability, Consortium

\section{Introduction}

Engineering, procurement and construction (EPC) contracts are the most common form of contract used to undertake construction works by the private sector on large-scale and complex infrastructure projects. Under an EPC contract a contractor is obliged to deliver a complete facility to a developer who need only turn a key to start operating the facility, hence EPC contracts are sometimes called turnkey construction contracts. In addition to delivering a complete facility, the contractor must deliver that facility for a guaranteed price by a guaranteed date and it must perform to the specified level. Failure to comply with any requirements will usually result in the contractor incurring monetary liabilities.

It is timely to examine EPC contracts and their use on infrastructure projects. A number of contractors have suffered heavy losses and, as a result, a number of contractors now refuse to enter into EPC contracts in certain jurisdictions. This problem has been worsen by a substantial tightening in the financial $\&$ insurance market. Construction insurance has become more expensive due to significant losses suffered on many projects. With the result there is huge question mark on the lenders concern over financial risks and bankability of project. However EPC Contracts will continue to be predominant form of construction contract used on large scale infrastructure projects in most jurisdictions.

A bankable contract is a contract with a risk allocation between the contractor and the project company that satisfies the lenders. Lenders focus on the ability of the contractor to claim additional costs or extensions of time as well as the security provided by the contractor for its performance. The less comfortable the lenders are with these provisions the greater amount of equity support the sponsors will have to provide. In addition, lenders will have to be satisfied as to the technical risk. Obviously price is also a consideration but that is usually considered separately to the bankability of the contract because the contract price goes more directly to the bankability of the project as a whole. In the context of detailed engineering and construction delivery, lenders will prefer for one financially strong party to accept full responsibility for the delivery of the works on time, on budget and to meet the required technical and performance specification. The key candidates in this regard are typically large recognised engineering and construction contractors.

The identity of the various parties working in contract can certainly have an impact on the lenders. The importance of achieving single point of responsibility relates to a desire by the lenders to see the party with the 'deepest pockets' bearing the entire risk of project delivery. To the extent that more than one party is responsible for delivery of the works (in terms of direct liability to the Sponsor). 


\section{Financing Structures and Lending Institutions}

The most common form of financing for infrastructure projects is project financing. Project financing is a generic term that refers to financing secured only by the assets of the project itself. Therefore, the revenue generated by the project must consist of running productive equipment to generate saleable product at a reasonable and comfortable price which in return will be sufficient for lenders / financers they have to keep watch on workability. Project financing is also often referred to as either non-recourse financing or limited recourse financing.

The terms non-recourse and limited recourse are often used interchangeably, however, they mean different things. Non-recourse means there is no recourse to the project sponsors at all and limited recourse means, as the name suggests, there is limited recourse to the sponsors. The recourse is limited both in terms of when it can occur and how much the sponsors are forced to contribute. In practice, true non-recourse financing is rare. In most projects the sponsors will be obliged to contribute additional equity in certain defined situations.

Large scale projects like power projects are financed on what is commonly referred to project finance basis (limited recourse), which essentially means that the lenders are looking at the repayment of the loan from the revenues to be generated by the project itself rather than repayment of the loan from the sponsor. Therefore, it is of paramount importance that the project contracts are drawn in a manner as to make the project bankable or in other words the project should be sufficiently attractive in terms of returns and all risks typically associated with the project should be duly addressed. In case the lenders are not satisfied with the way the risks have been addressed then the equity exposure of the sponsors may be greater.

\section{Assessment Of Financial Risks}

Setting up large scale projects require substantially large sum of money and are usually long drawn affairs. Projects of such nature are usually fraught with several risks, whether perceived or real. The nature of risks vary depending on which stage the project is at, for instance the risks during the construction period would be different from risks during the operating period. Each of these risks needs to be adequately addressed to ensure that a project is successfully constructed and operated. To a great extent these risk can be and are usually addressed through appropriately drafted project contracts. Perhaps the greatest exposure that a project has to risks is during the construction phase and also commissioning, effective running and outcome of process. However the present discussion would be limited to risks arising during the construction phase of the project.

In assessing bankability lenders will look at a range of factors and assess a contract as a whole. Therefore, in isolation it is difficult to state whether one approach is or is not bankable. However, generally speaking the lenders will require prequalification and bankability for selected consortium/ contracting agency the following:

1. Fixed completion date,

2. A fixed completion price,

3. Output/ performance guarantees,

4. No or limited technology risk,

5. Liquidated damages for both delay and performance

6. Security/guarantees from the contractor and/or its parent company;

7. Restrictions on the ability of the contractor to claim extensions of time and additional cost ; and

8. Single point responsibility.

An EPC contract delivers all of the requirements listed above in one integrated package. This is one of the major reasons why they are the predominant form of construction contract used on large-scale project financed infrastructure projects. An illustrative flow chart for project contract is shown below: 


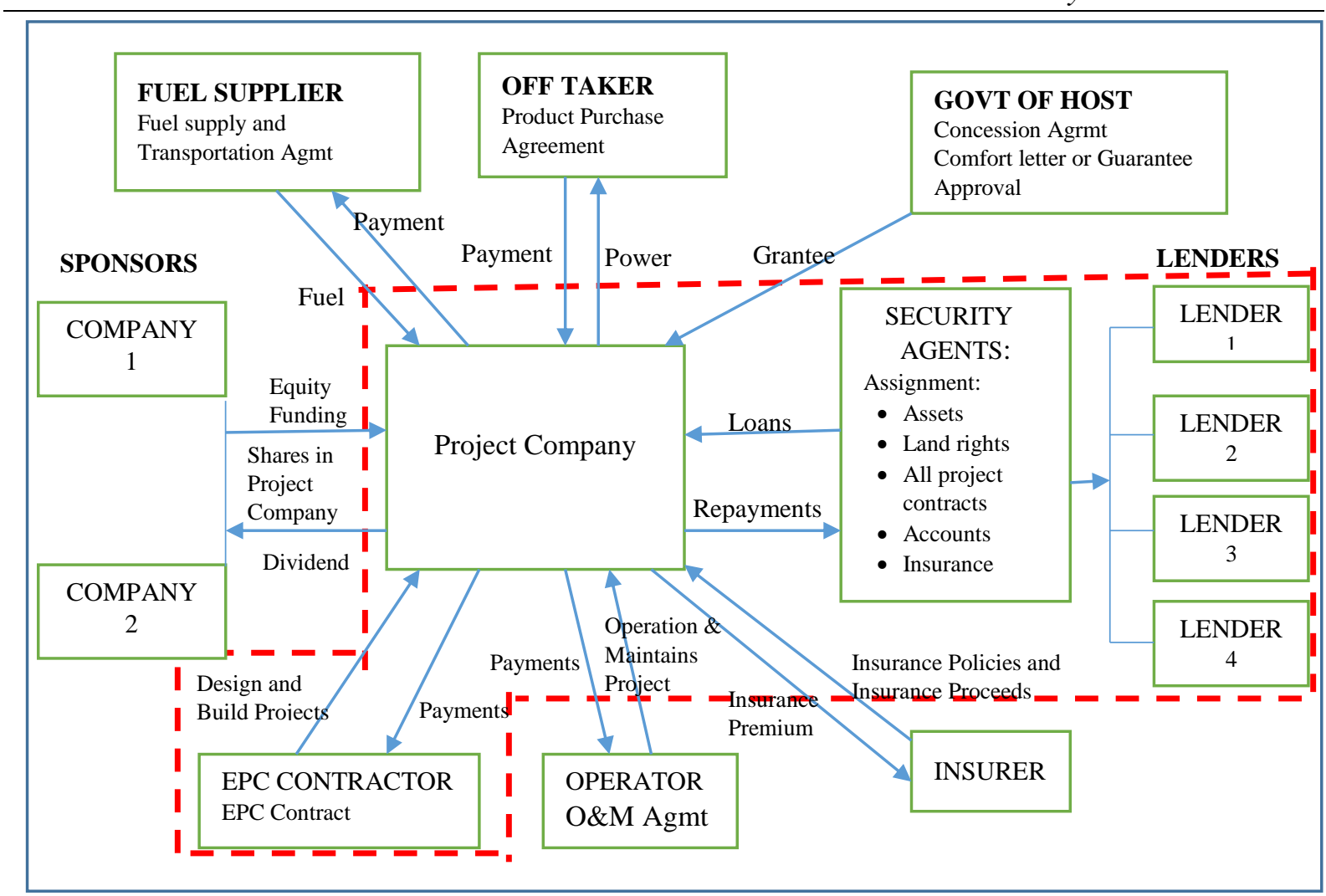

FLOW CHART FOR PROJECT CONTRACT

The EPC contract is the primary tool for allocation of risks between the project company and the contractors and to a certain extent also provides a level of protection to the lender by providing for overall coordination and single point responsibility. Some of the risks to a certain extent can be addressed through other forms of contracts as well for instance the entire works for the project can be broken down into several packages and accordingly contracted out to different contractors or the same contractor as well. However, in such an approach the biggest risk that arises is the possibility of the lack of coordination amongst the various contractors in executing the works for the project. EPC contracts, mitigate to a great extent the various risks associated with the project. Given below is an illustrative list of risks that are caused through an EPC contract:

1. Securities/guarantees: Most EPC contracts would require that the EPC contractor furnish adequate securities/ guarantees from reputable banks to ensure due performance by the contractor. At times, in addition to bank guarantees the EPC contractors are also required to provide guarantees from their parent entities.

2. Permits/Approvals: Large scale projects requires several approvals from governmental authorities and regulatory bodies, including environmental clearances. The EPC contractor remains responsible for obtaining and maintaining a great part of all such required approvals. The EPC contractor would be required to obtain not only those permits in its own name but also those needed in the name of the Project Company. Of course needless to mention the project company would be required to provide adequate support to the EPC contractor in this regard.

3. Price risk: The EPC contract would be a fixed price lump sum turnkey contract. Most EPC contracts have very limited scope for any change in the lump sum price.

4. Subcontracting risks: The EPC contractor remains liable for all acts and omissions of the subcontractors, including all payment responsibilities and performance related issues of the subcontractors. As mentioned earlier, some of the issues highlighted above may also be addressed through other forms of the contracts and not necessarily through EPC contracts. Also, whether an EPC contract is entered into or not would also depend on the sector in which the project is being undertaken. Given that the nature of risks associated with each projects would be different it is imperative to carefully examine and analyze each such risk and to properly allocate such risks. Such careful analysis would not only address the lenders' concerns but also enable each party to manage their risks effectively and make the project a success.

5. Completion risk: The completion risk is undertaken by the EPC contractor as it remains liable to pay liquidated damages for delay in case of any time overruns. The liquidated damage payable by the contractor is usually a percentage of the contract price. 
6. Extension of time/ additional costs: The grounds on which the E.PC contractor can ask for extension in the completion schedule and additional compensation are limited. Certain restricted events like force majeure, change in law, variations, etc. may give rise to occasions where the EPC contractor would be entitled to an extension in the completion schedule and/or additional cost. However, it is not necessary that because an event has arisen which requires an extension of time it would lead to additional costs also and vice versa.

7. Performance risk: The EPC contract would guarantee that the technology used for the project would be capable of delivering the desired outputs failing which the EPC contractor would be liable for payment of liquidated damages for under performance.

8. Defects liability / latent defects liability: The EPC contract would provide that the EPC contractor would remain liable for any defects in the works for a certain period of time. Usually in India the defects liability period in India varies from 12 months to 24 months and under certain circumstances the defects liability period may be extended subject to an overall capped period. At times the EPC contractor also remain liable for latent defects, which usually are for a longer duration than the defects liability period. However, typically an EPC contractor would be Liable for Latent defects only if the EPC contractors has done the designing for the project itself.

\section{Structuring/ Split Of EPC Contract}

At times EPC contractors act as a consortium and each contractor in the consortium remains responsible for different portion of the works. To ensure that the works are properly performed the members of the consortium must coordinate and integrate their respective works. The EPC contract must permit such cooperation and integration while at the same time keeping intact the principle of single point responsibility.

Since there could possibly be more than one contractor for a project and also different taxation regimes different contracting structures may need to be adopted to carry out the works effectively and at the same time make such EPC contracts cost and time effective.

EPC contracts can either be single consolidated EPC contract or split structure EPC contract. In a single consolidated EPC contract structure the entire works, i.e. all the supplies and services are performed under one contract. From a project company's and lenders perspective perhaps a single consolidated EPC contract may be the most attractive in terms of single point responsibility and in terms of enforceability' of the contract, however, the price payable for such consolidated contract arc likely to be significantly higher for various tax reasons. Also many times contractor has to collaborate with specialist agencies, offshore contractors to form a special consortium \& a company made only for this project. In such case even though respective responsibility has been taken by independent agency over all single point agency still remains with consortium. Therefor lender has to take a decision for selection of an agency considering various aspects including tax benefits offered for such offshore contractors and also to the total consortium in execution while

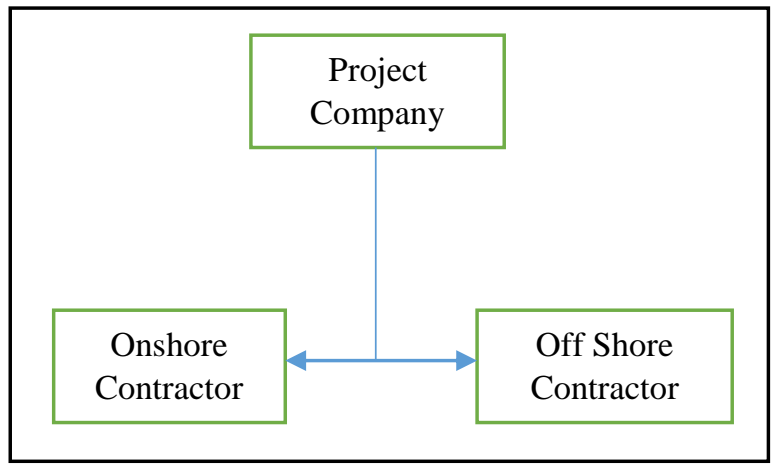
considering the EPC structure of selected agency.

In a split EPC contract structure the entire work are divided into separate contracts. For instance, assuming there is an offshore component in the works then there could be an onshore supply and services contract and an offshore supply and services contract. This could be further split into onshore services contract, onshore supply contract, offshore services contract and offshore supply contract. The aforesaid is a fairly straight forward simple split structure and certain split structures could be quite complicated. Such complicated structures mar need to be adopted depending upon the objectives sought to be achieved.

Split EPC structures however, dilutes the concept of single point responsibility of the contractor for performing the works for the project. For such large value contracts it is extremely critical from the project company's and the lenders perspective that the single point responsibility principle is retained and that in case of any non-performance or under-performance the project company does not have to pursue difference entities for delivering a fully completed and operational project and/or other remedies. 


\section{Conclusion}

Lenders have specific requirements at both the pre and post-contract stages of projects. Both the precontract process and the project contracts must be bankable if lender support is to be secured.

The EPC contract constitutes a large portion of the project cost. Therefore, apart from being satisfied that the project is financially viable, the primary interest of lenders during the pre-contract stage will be to ensure only well qualified credit worthy EPC contractors are considered.

The primary post-contract interest of lenders is to have the debt properly serviced. Therefore, bankability requires specific contractual allocation of risks. Furthermore, lenders will generally require that the equity funds be exhausted before debt is further extended so that unexpected difficulties encountered early in the project do not threaten lender funds.

Lenders provide most of the financing and stand to make lesser returns than the equity investors. Therefore, lenders are risk averse and use their strong bargaining position to delegate risk and maximises the probability of proper debt servicing even in the event of project difficulties.

\section{Reference}

[1]. A Guide to Project Management Body of Knowledge, (PMBOK) Fifth Edition, 2013 Project Management Institute, Inc

[2]. Damian McNair, EPC Contracts in Power Sector, www.dlapiper.com

[3]. Michael Dew, Bankability of construction contracts,2005, www.legaltree.ca

[4]. Pranjal Bora, Bankability and structuring of EPC Contracts, 2009, www.epcworld.in

[5]. David Z. Vance, EPC Contracts for Domestic and International Projects, 2006, Baker \& McKenzie 